\title{
Introduction to Special Issue of the Proceedings of the 8th Symposium on High Temperature Superconductors in High Frequency Fields
}

\author{
Hamid Kokabi' ${ }^{1}$ and Juan M. O'Callaghan²
}

Published online: 17 January 2007

This volume contains the papers presented at the 8 th Symposium on High Temperature Superconductors in High Frequency Fields held in Begur (Spain) on May 26-29th, 2004.

The event was the eighth in the series of biannual specialist symposia devoted to microwave properties and applications of high temperature superconductors (HTS). Attendees were from industrial, government and academic research organizations.

The meeting venue was the Parador de Aiguablava, located $146 \mathrm{~km}$ north of Barcelona, and $46 \mathrm{~km}$ east of Girona, on the Mediterranean coast. The place was chosen to promote discussion and exchanges between participants by keeping them together with a minimum of outside distractions in a pleasant surrounding.

The papers in this volume are grouped using the same categories used to classify papers at the symposium:

- Commercial Applications \& ApplicationRelated Issues

\footnotetext{
${ }^{1}$ Université Pierre et Marie Curie (UPMC), Paris, France; e-mail: kokabi@ccr.jussieu.fr.

${ }^{2}$ Technical University of Catalonia (UPC), Barcelona, Spain.
}

- Fundamentals

- Novel/Future Opportunities for HTS

- Materials Issues-MgB2

- Methods for Linear and Nonlinear Measurements of HTS Materials

- Submillimeter Technology

We would like to thank the members of the HTSHFF committee (H. Chaloupka, B. A. Willemsen, H. Piel, A. Porch, S. Sridhar, R. Withers, S. A. Wolf, D. VanVechten, and R. Vaglio), and the organizer of the previous symposium (D. Oates) for their assistance and advice in the organization of the 8th symposium.

We also wish to thank the following for their contribution to the success of this conference:

European Office of Aerospace Research and Development, Air Force Office of Scientific Research, United States Air Force Research laboratory. Spanish Ministry of Education and Science. 